Effect of corrosion on the bond between steel and concrete: an overview K. Lundgren

Published in Magazine of Concrete Research, see journal homepage http://www.icevirtuallibrary.com/content/journals

"Permission is granted by ICE Publishing to print one copy for personal use. Any other use of these PDF files is subject to reprint fees." 


\title{
Effect of corrosion on the bond between steel and concrete: an overview
}

\author{
K. Lundgren \\ Chalmers University of Technology
}

The volume increase that takes place when reinforcement in concrete corrodes causes splitting stresses in the concrete. Thereby, the bond between the reinforcement and the concrete is influenced. This effect has been studied both experimentally and theoretically by many researchers. In the current paper, the effect of corrosion on the bond between reinforcement and concrete is investigated and described in a systematic way. Literature studies of experimental work are combined with finite element analyses of different cases. In this way, modelling is used as a tool to give the basic understanding, and the results are compared with experiments. An overview of the effect depending on the reinforcement type, existence of transverse reinforcement and confinement owing to concrete and boundaries is given. This overview is intended to be of help in understanding the phenomena as well as in assessment of existing structures.

\section{Introduction}

During recent years, much research concerning durability aspects of reinforced concrete has been done. Lifetime design based on probabilistic approaches has been developed; see e.g. Duracrete. ${ }^{1}$ A rather common approach is to assume (on the safe side) that the lifetime is ended when corrosion is initiated. However, if the structural effects of corrosion are not checked in the lifetime design, initiation can only be allowed to occur with a very small probability. This will in many cases lead to unreasonably large concrete covers. To be able to use covers of more practical size, it is often necessary to include the structural effects of corrosion in the lifetime design. Hence there is a need for models of how corrosion affects the structure. The most severe effect of reinforcement corrosion is the volume increase, which causes splitting stresses in the concrete, and thus affects the bond between the reinforcement and the concrete. This has been studied by many researchers; for a state-ofthe-art report see reference 2. Results of Li and Zheng ${ }^{3}$ also show that the structural degradation of bond shows more variation than degradation in stiffness and strength.

Department of Civil and Environmental Engineering, Division of Structural Engineering, Concrete Structures, Chalmers University of Technology, SE-412 96 Göteborg, Sweden

(MCR 51462) Paper received 22 November 2005; last revised 20 October 2006; accepted 5 February 2007
When starting to study bond between reinforcement and concrete, it is easy to become confused. Different bond mechanisms are often mixed with different failure modes. The confusion may grow when the effect of corrosion on bond is studied. General conclusions such as how a certain degree of corrosion affects the bond to a certain degree vary quite a lot, and it is difficult to obtain an overview. It is well known that parameters such as the surrounding structure and type of reinforcement have a strong influence both on the bond behaviour for uncorroded structures, and on the effect of corrosion on bond.

In the current paper, these influencing parameters are organised in a systematic way, and an overview of how corrosion affects the bond behaviour is given. Finite element modelling is used as a tool to provide the basic understanding. Furthermore, experiments from the literature are examined to check the validity of the overview. The intention is that the overview can be used both as a tool for understanding and also when judging how dangerous corrosion is, for example upon assessment of existing structures.

\section{Modelling}

\section{General}

Modelling of the effect of corrosion on bond was done by the author in Lundgren., ${ }^{4,5}$ It has also been carried out by Berra et al., ${ }^{6}$ who modelled different 
levels of confinement for ribbed bars. The main difference between these studies is that, while Berra and coworkers modelled the geometry of the ribs, the present author chose to model the bars with a smooth surface, instead including the effect of the ribs in a frictional model. This makes it possible easily to change the surface properties, for instance from ribbed to smooth bars, simply by changing the input of the frictional model.

The modelling method used is especially suited for detailed three-dimensional finite element analyses, using solid elements for both the concrete and the reinforcement. Special interface elements were used at the surface between the reinforcement bars and the concrete to describe a relation between the traction and the relative displacement in the interface. The interface elements include a frictional bond model and a corrosion model, which can be viewed as two separate layers around a reinforcement bar; see Fig. 1 .

\section{Bond}

The bond mechanism is the interaction between reinforcement and concrete. It is considered to be a result of three different mechanisms: chemical adhesion, friction and mechanical interlocking between the ribs of the reinforcement bars and the concrete; see e.g. ACI. ${ }^{7}$ The mechanical interlocking can, however, be viewed as friction, depending on the level at which the mechanism is considered. For ribbed bars, the inclined forces resulting from the bearing action of the ribs make it possible to continue to transfer forces between the reinforcement and the concrete, after the chemical adhesion is lost. The inclined stress is often divided into a longitudinal component, denoted the bond stress, and a radial component, denoted normal stress or splitting stress; see Fig. 2.

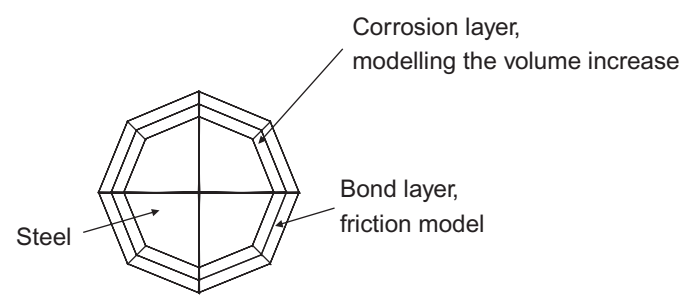

Fig. 1. The frictional bond model and corrosion model can be viewed as two separate layers around a reinforcement bar

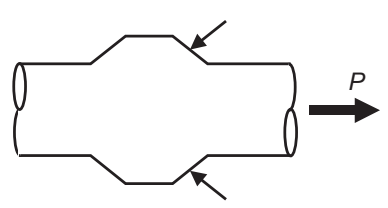

(a)

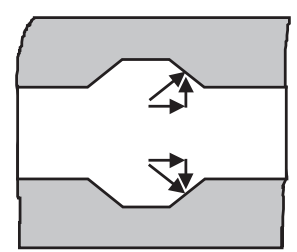

(b)
Fig. 2. Bond and splitting stresses between a deformed bar and the surrounding concrete (Magnusson ${ }^{8}$ ): (a) stress on the reinforcing bar; (b) stress on the concrete and its components
A frictional model for the bond between ribbed reinforcement and concrete was used; for details see Lundgren. ${ }^{9}$ For analyses of smooth bars, adhesion was added to the model. The reason is that for ribbed bars, the adhesion contributes to only a small part of the bond, while for smooth bars, the ability to develop normal stresses during slip is much smaller. Thereby, the bond capacity owing to friction is strongly reduced, and thus the adhesion is no longer negligible; see also Bolmsvik and Lundgren. ${ }^{10}$

The stresses are limited by two functions; see Fig. 3. One function $\left(F_{1}\right)$ describes the friction, including the adhesion. The other function $\left(F_{2}\right)$ describes the upper limit, which is determined from the stress in the inclined struts in the concrete that results from the bond action, limiting the compressive and tensile stresses. As can be seen in Fig. 3, the maximum bond capacity that can be obtained is roughly half the compressive stress that can be carried in the inclined struts, that is, roughly half the compressive strength of the concrete. When the stresses are limited by the function describing the friction, normal stresses are generated. Thus, the model used describes the basic mechanisms of bond such as

(a) adhesion

(b) friction

(c) ability to cause normal stress at slip

(d) upper limit determined by failure of the concrete between the ribs.

By the use of this local model, and by modelling the bar itself and the surrounding structure with solid elements, the global behaviour with different failure modes is obtained as a result of the analyses. Examples of such failure modes are pull-out failure, splitting failure and loss of bond owing to yielding of the reinforcement. Another phenomenon which is obtained as a result of the analyses is the Poisson effect at pre-stress release.

\section{Corrosion}

The corrosion products occupy a larger volume than the steel they were formed of, which leads to splitting stresses acting on the concrete. Some authors also claim

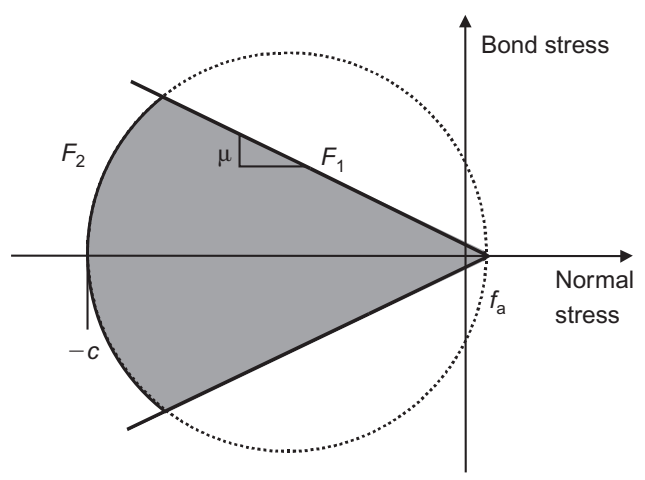

Fig. 3. The yield surface in the frictional bond model

Magazine of Concrete Research, 2007, 59, No. 6 
that the corrosion products form a weak layer, and therefore reduce the friction. Cairns et al., ${ }^{11}$ however, carried out friction tests which indicated that corrosion products do not reduce the friction characteristics.

The volume increase of the corrosion products compared to the virgin steel was modelled in a corrosion layer, as described by Lundgren. ${ }^{5}$ As the rust is not free to expand, it is important to include the mechanical behaviour of the rust itself. Following the results in Lundgren, ${ }^{5}$ it was assumed that the rust behaves like a granular material; that is, its stiffness increases with the stress level. This behaviour is also confirmed in measurements by Ouglova et al. ${ }^{12}$ Furthermore, for ribbed bars, it was assumed that corrosion affects the friction between the steel and the concrete. Rather large corrosion penetrations were assumed to be needed, however, before the friction decreased; this corresponds to assuming that only corrosion attacks of such magnitude that they influence the size of the ribs will affect the friction.

\section{Finite element models}

To investigate different typical cases, axisymmetric analyses were carried out. The geometry in these analyses is shown in Fig. 4. The reinforcement had a diameter of $20 \mathrm{~mm}$, while the cover was varying; see Table 1. In analyses where transverse reinforcement was present, $2 \varnothing 6$ were placed as shown in Fig. 4, with a distance from the main reinforcement, $a$, as tabulated in Table 1.

For every modelled geometry, several analyses were carried out. Each analysis started by modelling the corrosion process to varying corrosion levels by applying time steps. Thereafter, a deformation-controlled pull-out force was applied.

In some of the analysed cases, meshes of varying density were used; see examples in Figs 4(b) and (c).
The results in these analyses corresponded well; thus, no mesh dependence was found.

The concrete was modelled with a constitutive model based on non-linear fracture mechanics, using a rotating crack model based on total strain; see TNO. ${ }^{13}$ Axisymmetric models were used, assuming four radial cracks. For the tension softening, the curve by Hordijk et al. was chosen, as described in TNO. ${ }^{13}$ In compression, an ideal plastic behaviour was used, assuming a compressive strength of $40 \mathrm{MPa}$. Other necessary material data for the concrete were estimated according to the expressions in CEB. ${ }^{14}$ Thus, the Young's modulus used was $34.2 \mathrm{GPa}$, Poisson's ratio $0 \cdot 15$, tensile strength $3 \cdot 0 \mathrm{MPa}$, and fracture energy $79 \cdot 2 \mathrm{~N} / \mathrm{m}$. The elastic modulus of the reinforcement was assumed to be $200 \mathrm{GPa}$, and Poisson's ratio was $0 \cdot 3$.

The input for the bond model for ribbed bars was as described in Lundgren, ${ }^{9}$ and for smooth bars based on the work in Bolmsvik and Lundgren. ${ }^{10}$ The input for the corrosion model was as described in Lundgren. ${ }^{5}$ All chosen parameters are tabulated in Table 1.

\section{Effect of corrosion on the bond for ribbed bars}

\section{Identification of important factors}

To better understand the effect of corrosion on bond, several cases have been distinguished. This requires determination of the most important influencing factors. In the overview here, it was decided to include three factors

(a) reinforcement type (ribbed or smooth)

(b) whether transverse reinforcement is present or not

(c) whether there are splitting cracks at uncorroded

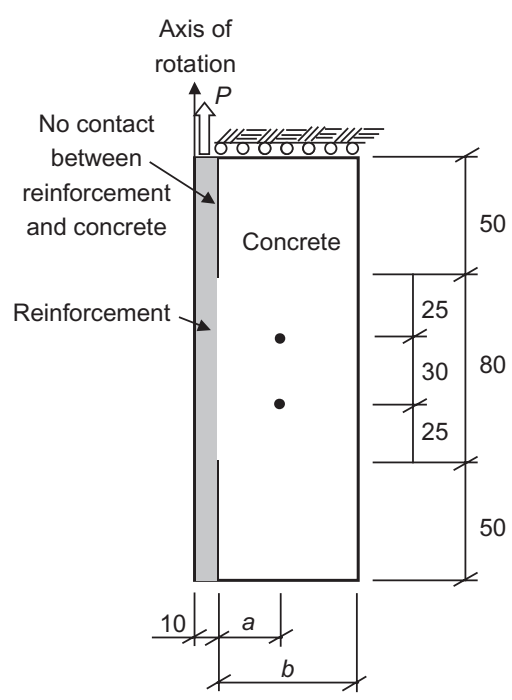

(a)

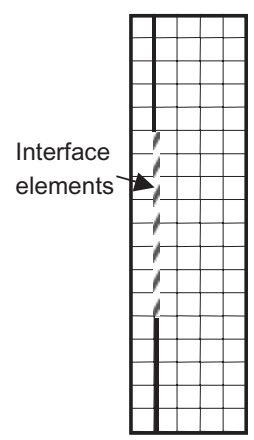

(b)

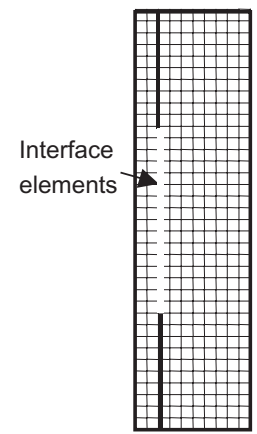

(c)

Fig. 4(a) Dimensions and boundaries in the finite element analyses. Measurements in mm. (b) and (c) examples of meshes used; one coarse and one dense mesh for the same geometry 


\section{Lundgren}

Table 1. Input in the analyses

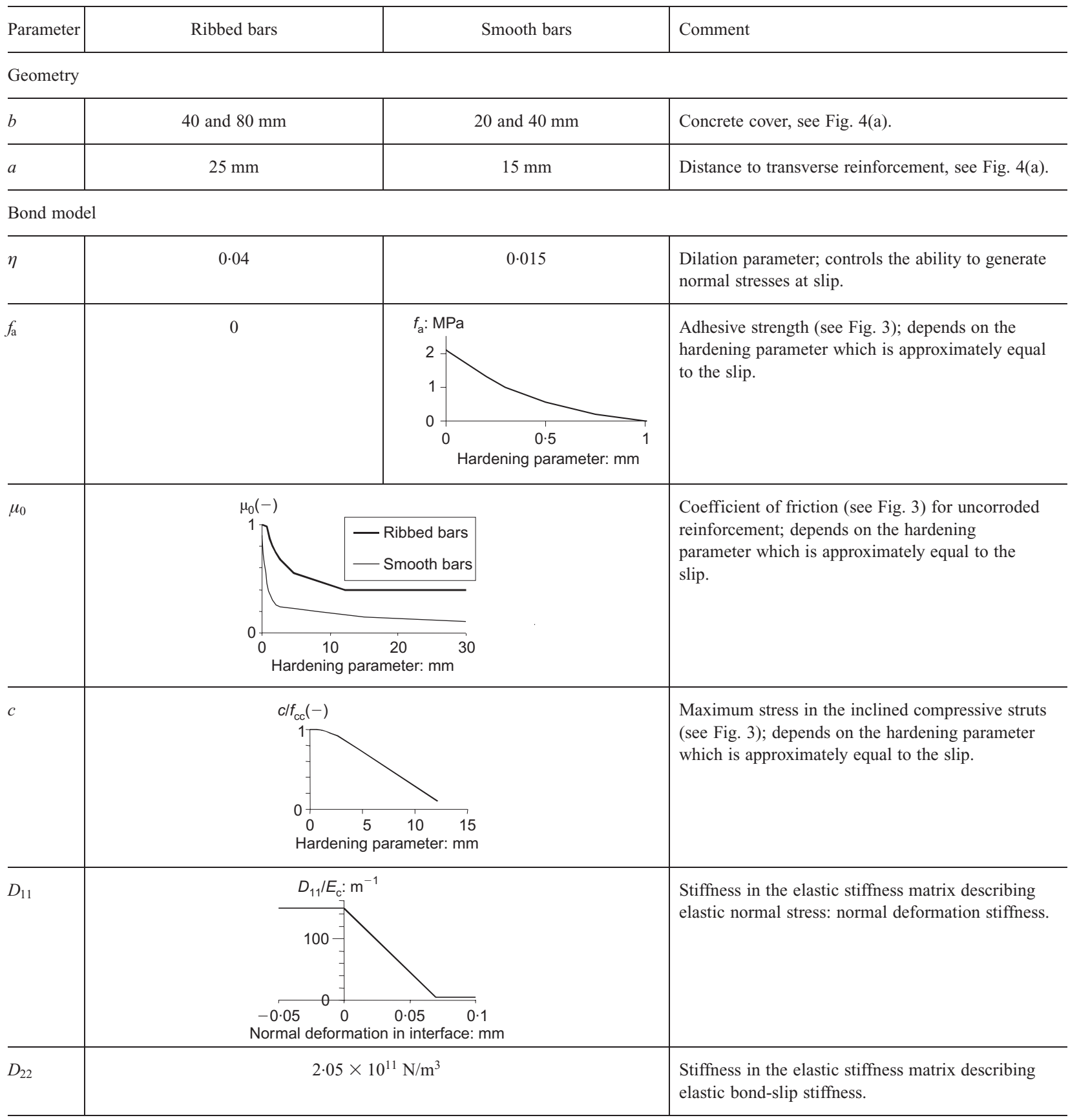

Corrosion model

\begin{tabular}{l|c|c}
\hline$v$ & $2 \cdot 0$ & Volume of the rust relative to the uncorroded steel. \\
\hline$K_{\text {cor }}$ & $14 \cdot 0 \mathrm{GPa}$ & $\begin{array}{l}\text { Parameters describing the mechanical behaviour of } \\
\text { the rust. }\end{array}$ \\
\hline$p$ & $7 \cdot 0$ & \\
\hline
\end{tabular}

(continued) 
Table 1. (continued)

\begin{tabular}{|c|c|c|c|}
\hline Parameter & Ribbed bars & Smooth bars & Comment \\
\hline$k$ & $\begin{array}{r}k(x / r)[-] \\
1.2 \\
0.8\end{array}$ & $1 \cdot 0$ & $\begin{array}{l}\text { Function describing the effect of corrosion on the } \\
\text { coefficient of friction; depends on corrosion } \\
\text { penetration divided with reinforcement radius. }\end{array}$ \\
\hline
\end{tabular}

pull-out or not, that is, whether splitting cracks would occur for anchorage failure if the reinforcement was uncorroded.

The choice of these factors can of course be discussed; for example, there are several further influential parameters. Some of them are: type of corrosion (general/ pitting, owing to chlorides or carbonation, wet or dry environment); amount of transverse reinforcement; placement of bar; possible effect of support pressure; and concrete strength. However, the three factors listed above were chosen because they were considered to have the greatest influence. Moreover, some of the listed possible parameters (such as support pressure and concrete strength) are indirectly included, as their main influence is on whether there will be splitting cracks at uncorroded pull-out or not. Another reason to use the chosen influencing factors is that these factors are rather clearly definable.

By use of the three factors above, an overview as shown in Fig. 5 can be sketched. In the work described here, this overview was at first established as a hypothesis. By investigating each of the separate cases in detail, it could be validated. In the following, each of these different cases for ribbed bars is described in more detail, with analyses and references describing the behaviour. For ribbed bars, there are four cases

(a) with transverse reinforcement; cover cracks at uncorroded pull-out

(b) with transverse reinforcement; cover does not crack at uncorroded pull-out

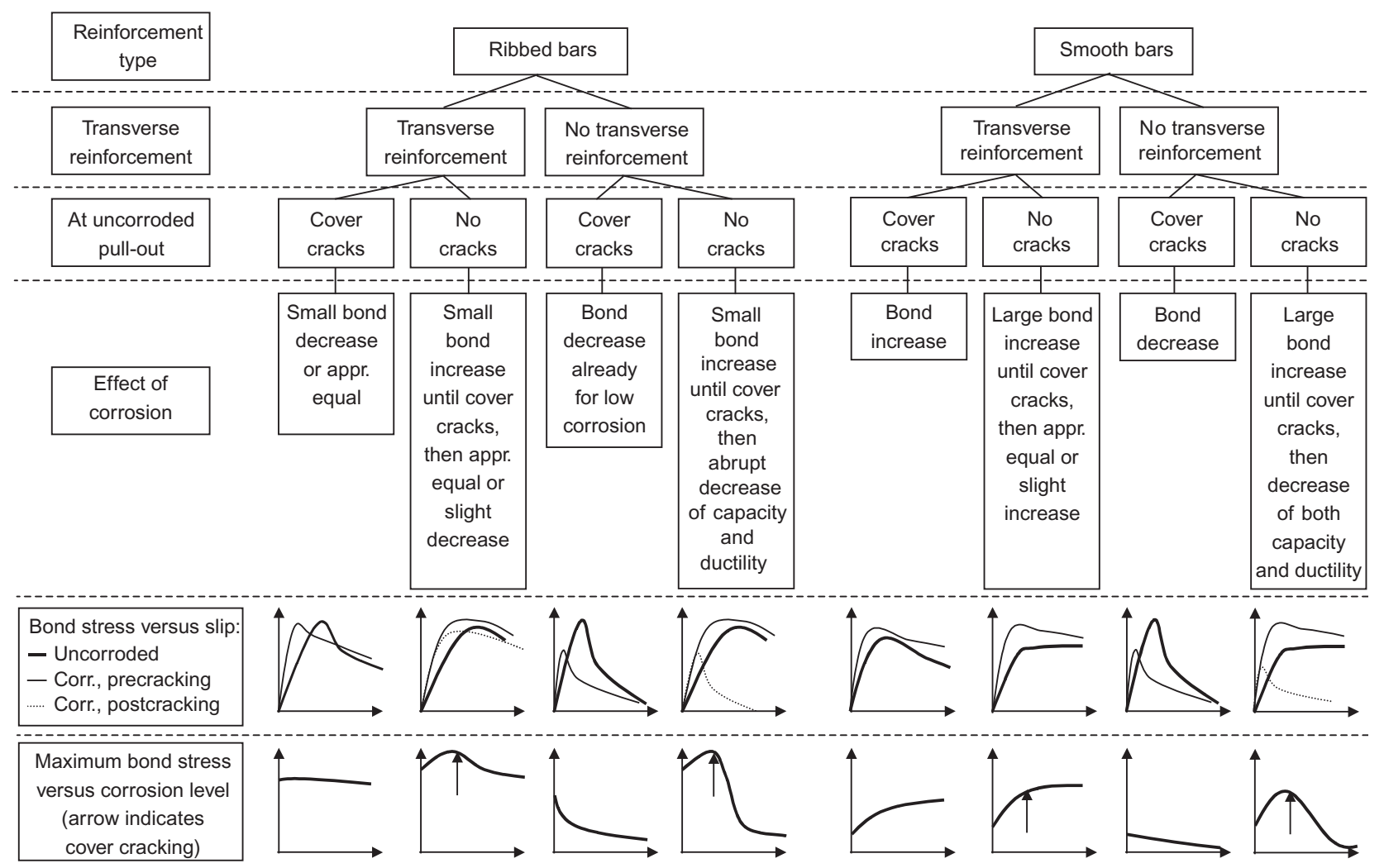

Fig. 5. Overview of effect of corrosion on bond 
(c) without transverse reinforcement; cover cracks at uncorroded pull-out

(d) without transverse reinforcement; cover does not crack at uncorroded pull-out.

\section{With transverse reinforcement; cover cracks at uncorroded pull-out}

For ribbed bars with large diameters combined with small concrete covers, the covers will crack at anchorage failure when the reinforcement is uncorroded unless the boundaries provide restraint to prevent cracking. This is a common situation, which is also commonly combined with transverse reinforcement.

Analyses studying this situation were carried out using axisymmetric models as described in the section on finite element models. The concrete cover ( $b$ in Fig. 4(a)) was $40 \mathrm{~mm}$; thus the cover to diameter ratio was 2.0. The results from these analyses are shown in Fig. 6. For uncorroded pull-out, a splitting crack reached the outer surface of the concrete when the bond stress was around $14 \mathrm{MPa}$. This decreased the stiffness; however, the bond stress could continue to increase until a maximum of $15.5 \mathrm{MPa}$ was reached. The transverse reinforcement kept the structure together, thus causing a ductile behaviour. Corrosion alone cracked the cover at a corrosion penetration around $50 \mu \mathrm{m}$. Corrosion increased the initial stiffness in the bond-slip behaviour; thus, the more corrosion, the smaller the slip when the maximum bond stress was reached. Regarding the bond capacity, a small increase could be noticed for corrosion penetra-

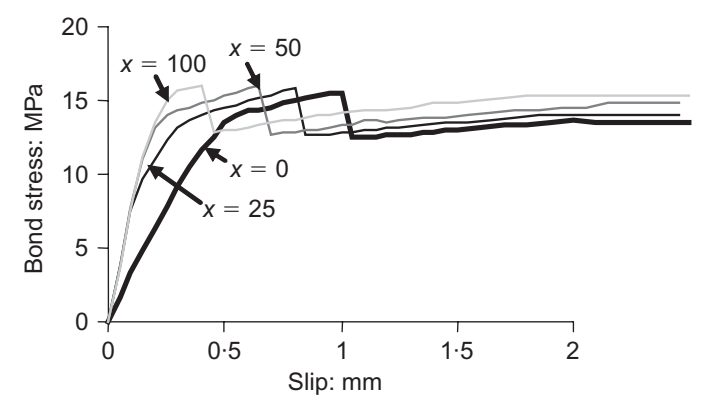

(a)

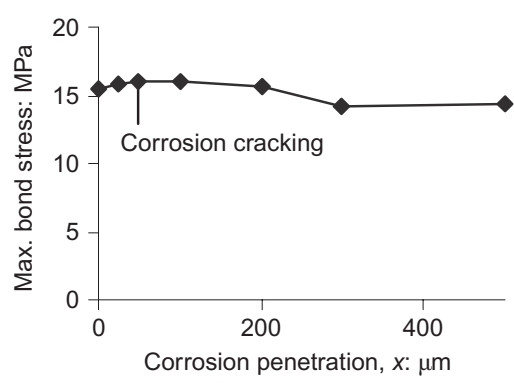

(b)

Fig. 6. Results from analyses with ribbed bars, with transverse reinforcement; cover cracks at uncorroded pullout. Cover $40 \mathrm{~mm}$, bar diameter $20 \mathrm{~mm}$ : (a) bond stress versus slip; (b) maximum bond stress versus corrosion penetration tions smaller than the one cracking the cover, and a small decrease for larger corrosion penetrations. These changes in capacity were very small.

These results can be compared with what has been measured in tests including transverse reinforcement and cover cracking at uncorroded pull-out. Al-Sulaimani et al. ${ }^{15}$ made beam tests with stirrups confining the main reinforcement. They measured a small increase in bond capacity for corrosion penetrations smaller than the one cracking the cover, and a small decrease in bond capacity for larger corrosion penetrations. Fang et al. ${ }^{16}$ measured almost constant bond capacities in pull-out tests. Lee et al. ${ }^{17}$ conducted pullout tests and reported reductions in bond capacities for very large corrosion levels. Coronelli ${ }^{18}$ combined transverse reinforcement with specially arranged so-called skin reinforcement, and measured increasing bond strength with increasing corrosion level, even after corrosion cracking. Shima ${ }^{19}$ reported pull-out tests with a rather large loss of bond; however, in these tests the transverse reinforcement was only arranged on one side of the bar with a rather small cover on the other side.

To conclude, for the case with confining transverse reinforcement and where the cover cracks at uncorroded pull-out, corrosion has only a minor effect on the bond behaviour. As the cover cracks for pull-out already without corrosion, the transverse reinforcement is keeping the structure together already for uncorroded specimens. If the cover cracks owing to corrosion, this does not have any major influence. For large corrosion penetrations, a small decrease in bond capacity can be seen, probably mainly because the ribs are being corroded. This behaviour can be seen both in analyses and in experimental results.

With transverse reinforcement; cover does not crack at uncorroded pull-out

For large covers combined with small reinforcement bars, the cover will not crack at anchorage failure of an uncorroded bar. This can also be true for larger bars or smaller covers, if the boundaries provide cracking restraint when, for example, there is support pressure acting. Both of these cases can be combined with transverse reinforcement.

No experiments have been found in the literature for this combination, with enough confinement to avoid cracking at uncorroded pull-out combined with transverse reinforcement. The main reason for this is most likely that, when transverse reinforcement has been arranged in tests, the cover used has been rather small to be similar to existing structures. However, as mentioned above, this is a possible combination, for example at supports or if small bar diameters are used.

Analyses of this case were carried out with a concrete cover of $80 \mathrm{~mm}$, giving a cover-to-diameter ratio of 4.0 . The results from these analyses are shown in Fig. 7. For uncorroded pull-out, a maximum bond capacity close to half the compressive strength was reached, 


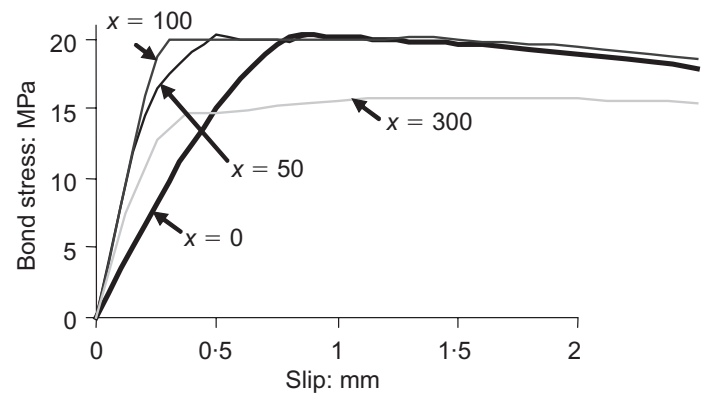

(a)

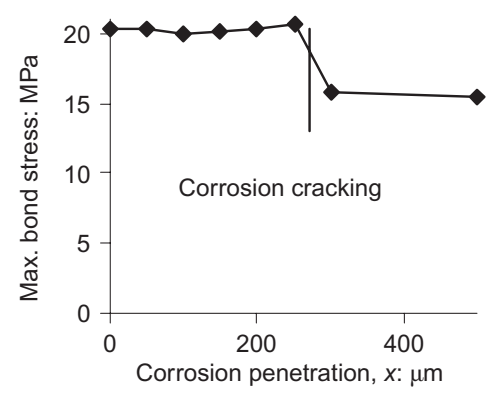

(b)

Fig. 7. Results from analyses with ribbed bars, with transverse reinforcement; cover does not crack at uncorroded pull-out. Cover $80 \mathrm{~mm}$, bar diameter $20 \mathrm{~mm}$ : (a) bond stress versus slip; (b) maximum bond stress versus corrosion penetration

i.e. around $20 \mathrm{MPa}$. Corrosion cracked the cover at a corrosion penetration around $270 \mu \mathrm{m}$. Corrosion increased the initial stiffness in the bond-slip behaviour; thus, the more corrosion, the smaller the slip when the maximum bond stress was reached. The maximum bond capacity remained almost unaffected by the corrosion for corrosion penetrations smaller than the one cracking the cover. For larger corrosion penetrations, the capacity decreased to the same level as for the case with transverse reinforcement but with a smaller cover, that is, around $15 \mathrm{MPa}$. For further increase of the corrosion, the bond capacity remained almost unaffected. Also the initial stiffness decreased for larger corrosion penetrations, compared with the maximum stiffness which was obtained just before the cover was cracked. As the transverse reinforcement kept the structure together, a ductile behaviour was obtained in all analyses.

In conclusion, for the case with transverse reinforcement and where the cover does not crack at uncorroded pull-out, the effect of corrosion will be slightly different depending on whether the corrosion penetration will crack the cover or not. For corrosion penetrations that do not cause cracking of the cover, the maximum bond capacity will remain almost unaffected, or even increase slightly. At the corrosion penetration that causes cracking of the cover, the maximum bond capacity will decrease to a smaller level, which will decrease only slightly for larger corrosion penetrations.
This smaller level depends on the amount of transverse reinforcement.

\section{Without transverse reinforcement; cover cracks at uncorroded pull-out}

For small covers combined with large reinforcement bars, the cover will crack at anchorage failure for uncorroded bars. If no transverse reinforcement is present, the bond capacity will be limited already for uncorroded bars.

In axisymmetric models for this situation, the concrete cover was $40 \mathrm{~mm}$, that is, similar to the corresponding case with transverse reinforcement. The results from these analyses are shown in Fig. 8. For uncorroded pull-out, a splitting crack reached the outer surface of the concrete when the bond stress was just below $12 \mathrm{MPa}$. As there was no transverse reinforcement keeping the structure together, this resulted in a brittle failure. Corrosion alone cracked the cover at a corrosion penetration around $40 \mu \mathrm{m}$. Corrosion increased the initial stiffness in the bond-slip behaviour. The maximum bond capacity remained almost unaffected by corrosion for corrosion penetrations that did not crack the cover; however, for larger corrosion penetrations, the bond capacity decreased rapidly to almost zero.

These findings can be compared with experimental results on bond in corroded specimens without transverse reinforcement, and where the cover cracks at

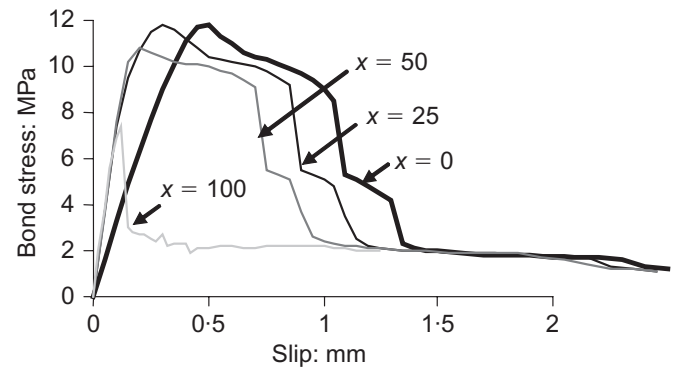

(a)

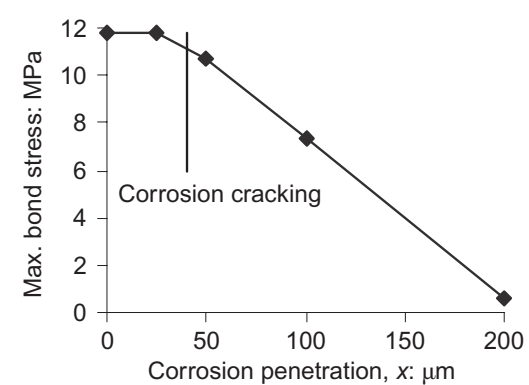

(b)

Fig. 8. Results from analyses with ribbed bars, without transverse reinforcement; cover cracks at uncorroded pullout. Cover $40 \mathrm{~mm}$, bar diameter $20 \mathrm{~mm}$ : (a) bond stress versus slip; (b) maximum bond stress versus corrosion penetration 
uncorroded pull-out. Mangat and Elgarf ${ }^{20}$ tested bond in beam tests according to RILEM's recommendations. They found a small bond increase until the corrosion penetration reached a critical level; thereafter the bond capacity decreased. Auyeung et al. ${ }^{21}$ report similar findings from pull-out tests. Stanish et al. ${ }^{22}$ tested beams and found decreasing bond capacity for increasing corrosion levels. Ghandehari et al., ${ }^{23}$ Lee et al., ${ }^{17}$ Shima ${ }^{19}$ and Fang et al. ${ }^{16}$ all carried out pull-out tests and reported that bond capacity decreased drastically with the corrosion level.

To conclude, for the case without transverse reinforcement and where the cover cracks at uncorroded pull-out, very limited corrosion will crack the cover. Thereafter, corrosion will decrease the bond capacity in a detrimental way. Similar findings can be found both in analyses and in experiments.

Without transverse reinforcement; cover does not crack at uncorroded pull-out

For large covers combined with small reinforcement bars, the cover will not crack at uncorroded pull-out. As discussed before, uncorroded pull-out might also not lead to cracking of the cover even for larger bars or smaller covers, if the boundaries provide cracking restraint when, for example, there is support pressure acting. If designing without taking corrosion into account, no transverse reinforcement is needed in these situations.

This case was analysed using a concrete cover of $80 \mathrm{~mm}$, that is, similar to the corresponding case with transverse reinforcement. The results from these analyses are shown in Fig. 9. In the analysis without corrosion, a pull-out failure was obtained with a maximum bond capacity close to half the compressive strength, that is, around $20 \mathrm{MPa}$. Corrosion cracked the cover at a corrosion penetration around $215 \mu \mathrm{m}$. For corrosion penetrations larger than that, the bond capacity decreased abruptly. For a corrosion penetration close to that level, the maximum bond capacity remained almost the same, but the failure mode changed from pullout to splitting failure, thus resulting in a brittle failure instead of the ductile behaviour obtained for smaller corrosion penetrations; see Fig. 9(a) and compare the curves for $x=0$ and $x=200 \mu \mathrm{m}$. Corrosion increased the initial stiffness in the bond-slip behaviour; thus, the more corrosion, the smaller the slip when the maximum bond stress was reached.

Several experimental results exist where the cover does not crack at uncorroded pull-out, and no transverse reinforcement is supplied. Almusallam et al. ${ }^{24}$ made cantilever bond tests; in these tests the loss of bond at the corrosion level which caused cracking of the cover was very pronounced. For smaller corrosion levels, the bond capacity was rather high, while it became very low when corrosion had cracked the cover. Pull-out tests by Al-Sulaimani et al., ${ }^{15}$ Cabrera and

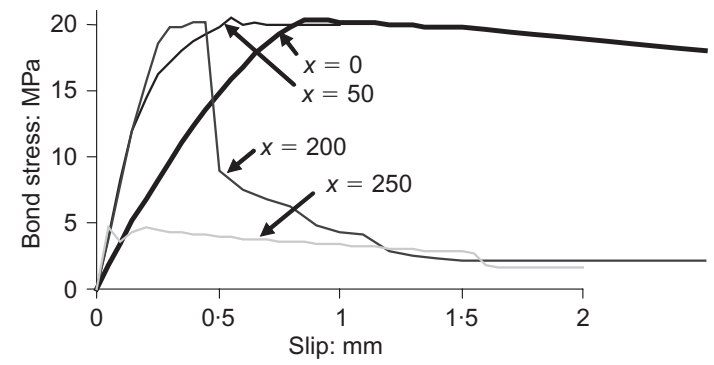

(a)

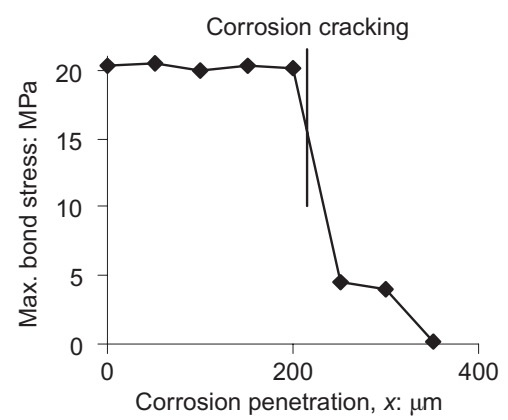

(b)

Fig. 9. Results from analyses with ribbed bars, without transverse reinforcement; cover does not crack at uncorroded pull-out. Cover $80 \mathrm{~mm}$, bar diameter $20 \mathrm{~mm}$ : (a) bond stress versus slip; (b) maximum bond stress versus corrosion penetration

Ghoddoussi, ${ }^{25}$ Ghandehari et al. ${ }^{23}$ and Hussein et $a l .{ }^{26}$ all show similar behaviour.

Thus, for the case without transverse reinforcement and where the cover does not crack at uncorroded pullout, both the bond capacity and ductility will be decreased in a detrimental way when the corrosion cracks the cover. For smaller corrosion penetrations, the bond capacity remains almost unaffected or even increases slightly. As the analyses presented here are axisymmetric, they can be expected to be more sensitive to cracking than is to be expected in real structures, as the concrete surrounding the reinforcement there does not crack in all directions at the same time. However, similar findings were found also in cantilever bond tests.

\section{General comments}

The behaviour for all different cases is summarised in Fig. 5. The scales in the bond-slip curves are varying, to make all graphs clearly visible. The scales in the maximum bond stress versus corrosion level graphs are, however, intended to be the same, to enable comparisons. Naturally, this summary is a simplification; for example, if the amount of transverse reinforcement is small, the behaviour will become close to that of specimens without transverse reinforcement. Also, of course, the transverse reinforcement can corrode; however, in general, larger corrosion penetrations are needed to change substantially the bearing capacity of

Magazine of Concrete Research, 2007, 59, No. 6 
the transverse reinforcement than to affect the bond of the main reinforcement. Granting these limitations, the summary in Fig. 5 is still believed to be of help in understanding the mechanisms, and for assessment of existing structures. One general observation for all cases is that corrosion increases the initial stiffness. The effect on the bond capacity varies more, depending on the presence of transverse reinforcement and the failure mode for uncorroded pull-out.

This variation of the effect on the bond capacity can be seen in Fig. 10(a), where the maximum bond stress from the various analyses with ribbed bars is plotted versus corrosion penetration. As can be seen, transverse reinforcement makes the bond much less sensitive to corrosion. Bond versus slip at various corrosion levels for the different analysed situations is shown in Figs 10(b)-(d). There, it can be seen that not only the bond capacity, but also the ductility, decreases with corrosion when no transverse reinforcement is present. In Fig. 11, the crack opening versus corrosion penetration is plotted from the various analyses. Only the part of the analyses where corrosion occurred is included; that is, the part where the pull-out force was applied is not included. The crack opening is calculated from the stress and strain in the grey-marked element in Fig. 11, thus corresponding to the crack opening at the surface of the concrete. The effect of transverse reinforcement

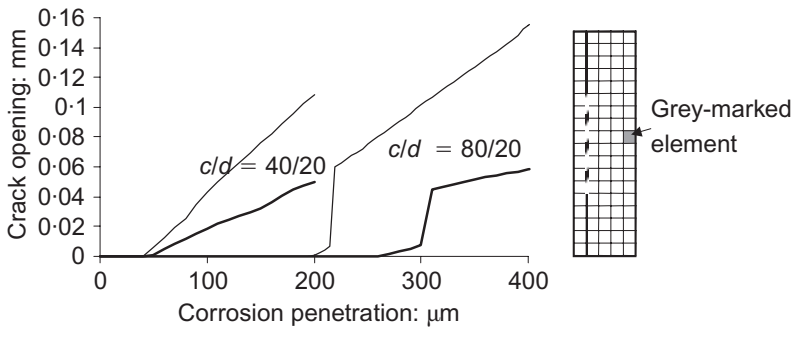

Fig. 11. Crack opening in grey-marked element versus corrosion penetration, thick lines with and thin lines without transverse reinforcement; results from axisymmetric analyses with ribbed bars

is especially interesting to note: it increased the corrosion level that cracked the cover to a very small degree, but limited the crack width.

\section{Effect of corrosion on the bond for smooth bars}

Also for smooth bars, it was chosen to distinguish several cases. As shown in Fig. 5, the same factors as for ribbed bars were chosen, that is, the existence of transverse reinforcement and whether there are splitting cracks at uncorroded pull-out or not. Again, these

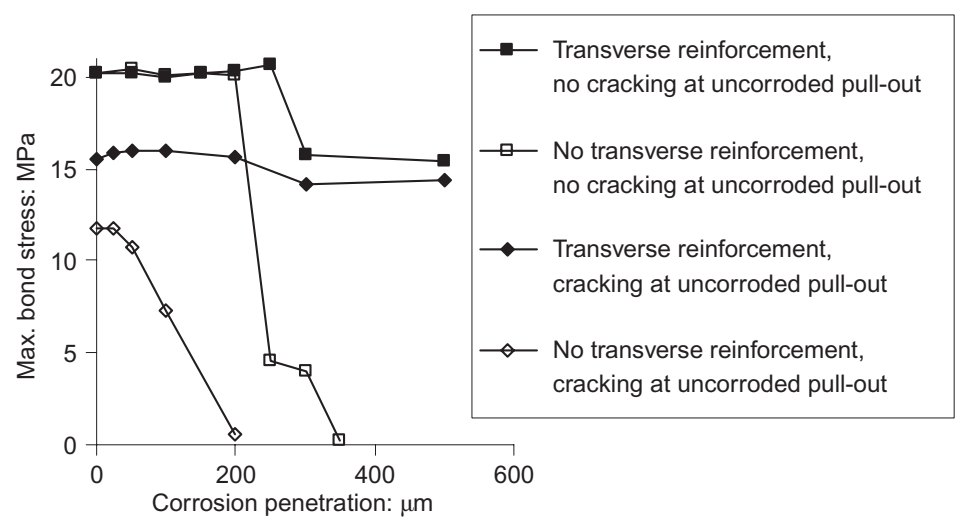

(a)

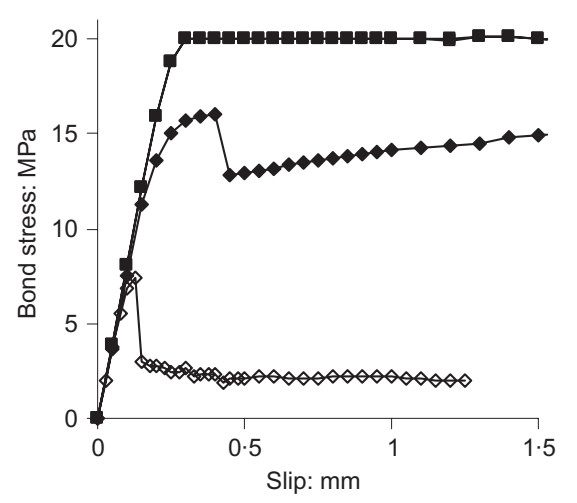

(c)

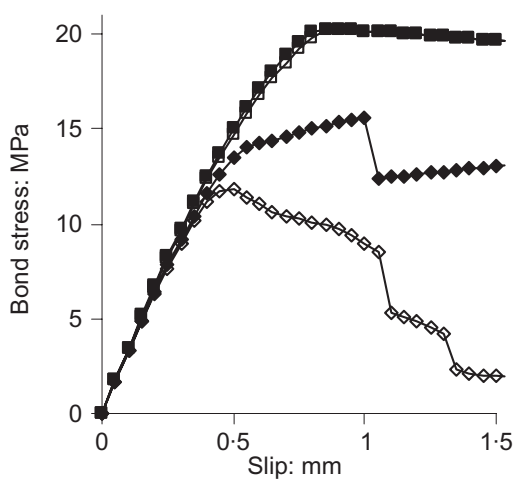

(b)

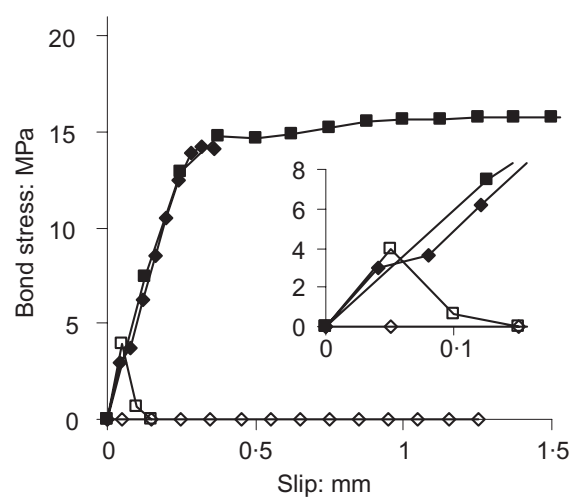

(d)

Fig. 10. results from axisymmetric analyses with ribbed bars. (a) Maximum bond stress versus corrosion penetration; (b), (c) and (d) bond stress versus slip at; (b) zero corrosion, (c) $100 \mu \mathrm{m}$ and (d) $300 \mu \mathrm{m}$, first part also enlarged 
choices can be discussed. It should be noted that for smooth bars, the cover generally does not crack at anchorage failure of an uncorroded bar. Furthermore, for smooth bars, there is a large difference between top-cast and bottom-cast bars, as has been shown in experiments of smooth corroded bars by Cairns et al. ${ }^{11,27}$ This difference is more important for smooth bars than for ribbed bars. The bond capacity for uncorroded smooth bars is lower for top-cast than for bottom-cast bars. Furthermore, there is a difference in the tendency to split the cover owing to corrosion. Cairns et $a l .{ }^{27}$ found that the top-cast bars could withstand a higher corrosion level before cracking of the cover than the bottom-cast bars. Thus, it could be debated whether this is a more important factor for smooth bars than if the cover cracks at uncorroded pull-out. Still, here it was chosen to use the same factors as for ribbed bars. The main reason for this choice was to facilitate comparison with ribbed bars.

It should be noted that even though the bond model has been calibrated and used for smooth bars in Bolmsvik and Lundgren, ${ }^{10}$ this model has not previously been used together with the corrosion model for smooth bars. Therefore, the experience of how these models work together is far smaller for smooth bars than for ribbed bars. Nevertheless, the results seem to be reasonable when comparing with available test results. Thus, even if the results cannot be trusted in detail to the same extent as for ribbed bars, they give a good indication of the expected behaviour in various situations.

In the following, each of the different cases with smooth bars is described in more detail, with analyses showing the behaviour. Generally, there are not as many experimental results available for smooth bars as for ribbed. For the cases where references have been found, these are presented.

\section{With transverse reinforcement; cover cracks at uncorroded pull-out}

As smooth bars generate far lower splitting stresses than ribbed bars, it is not common for smooth bars that the cover will crack if an uncorroded bar is pulled out. For very small covers, this is possible; however, such small covers are generally not used. To enable an overview, this case was nevertheless studied here, using axisymmetric models with a concrete cover of only $20 \mathrm{~mm}$, that is, with a cover-to-diameter ratio of $1 \cdot 0$. The results from these analyses are shown in Fig. 12. As adhesion was included in the analyses with smooth bars, the bond-slip curves have an initial very steep branch, where the bond stress is increased for very small slip. In the analysis without corrosion, the bond stress could be increased until about $1.75 \mathrm{MPa}$ before the yield line was reached. Thereafter, the stiffness decreased; still, the bond stress could be increased until about $4.8 \mathrm{MPa}$, when maximum was reached. At a slip of about $0.7 \mathrm{~mm}$, a splitting crack reached the outer

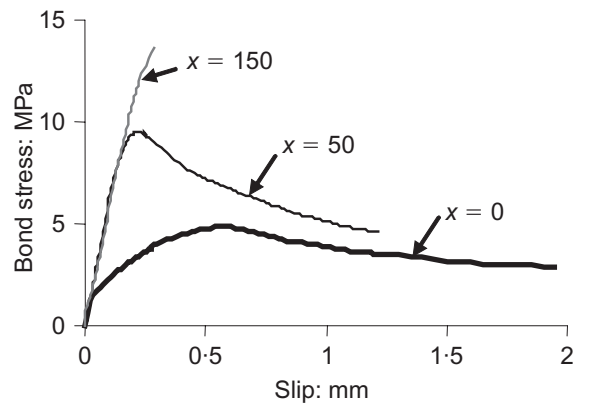

(a)

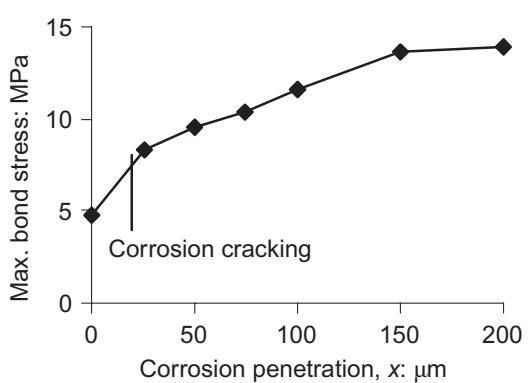

(b)

Fig. 12. Results from analyses with smooth bars and transverse reinforcement; cover cracks at uncorroded pullout. Cover $20 \mathrm{~mm}$, bar diameter $20 \mathrm{~mm}$ : (a) bond stress versus slip; (b) maximum bond stress versus corrosion penetration

surface of the concrete. The transverse reinforcement kept the structure together, thus causing a ductile behaviour.

Corrosion alone cracked the cover already at a corrosion penetration around $20 \mu \mathrm{m}$. However, owing to the transverse reinforcement, the crack width was limited; thus the cracks were about $0 \cdot 1 \mathrm{~mm}$ wide first at a corrosion penetration of around $450 \mu \mathrm{m}$. Corrosion increased the initial stiffness in the bond-slip behaviour; hence, the more corrosion, the smaller the slip when the maximum bond stress was reached. The maximum bond increased with increasing corrosion penetrations to a level of about $13 \mathrm{MPa}$ for a corrosion penetration of about $150 \mu \mathrm{m}$. For larger corrosion penetrations, the analyses became unstable when the maximum was reached. For lower corrosion levels, the ductility decreased in comparison to the uncorroded case.

To conclude, for the case with smooth bars, transverse reinforcement and where the cover cracks at uncorroded pull-out, corrosion will increase the bond capacity. No tests have been found in the literature with smooth bars including transverse reinforcement and cover cracking at uncorroded pull-out, most probably since this is not a very common case.

With transverse reinforcement; cover does not crack at uncorroded pull-out

As smooth bars do not generate any great splitting stresses, the covers do not need to be so large to

Magazine of Concrete Research, 2007, 59, No. 6 
prevent cracking at a pull-out loading of an uncorroded bar. The situation where the cover does not crack at uncorroded pull-out is therefore a common situation in real structures, which can be combined with transverse reinforcement.

In analyses studying this situation, axisymmetric models with a concrete cover of $40 \mathrm{~mm}$ were used; thus the cover-to-diameter ratio was $2 \cdot 0$. The results from these analyses are shown in Fig. 13. For uncorroded pull-out, the maximum bond capacity is much lower than for the corresponding situation with ribbed bars, around $6 \mathrm{MPa}$ compared to $20 \mathrm{MPa}$. Corrosion cracked the cover at a corrosion penetration around $55 \mu \mathrm{m}$. The maximum bond capacity increased quite a lot, to around $15 \mathrm{MPa}$, for corrosion levels smaller than the one cracking the cover; this is due to the positive effect of the corrosion-induced pressure. For larger corrosion levels, the bond capacity remained approximately constant at this high level. Corrosion also increased the initial stiffness in the bond-slip behaviour; however, it slightly decreased the ductility.

These results can be compared with test results. Cairns et ll $^{27}$ carried out beam end eccentric pull-out tests. In these tests, the cover was only $20 \mathrm{~mm}$ to $16 \mathrm{~mm}$ bars; still no cracking occurred at uncorroded pull-out. For the top-cast bars, the bond strength increased to the level of bottom-cast bars (i.e. roughly by a factor of 2) already for small corrosion levels. For higher corrosion levels, the bond capacity remained about the same. For bottom-cast bars, the bond capacity was almost unaffected by corrosion. Cairns et al. ${ }^{11}$ also carried out concentric pull-out tests with transverse

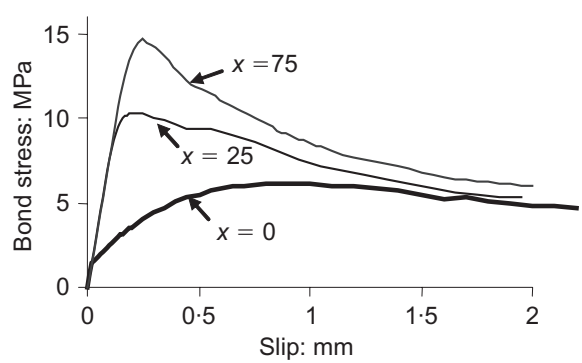

(a)

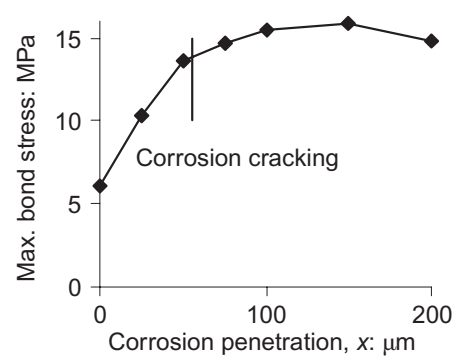

(b)

Fig. 13. Results from analyses with smooth bars, with transverse reinforcement; cover does not crack at uncorroded pull-out. Cover $40 \mathrm{~mm}$, bar diameter $20 \mathrm{~mm}$ : (a) bond stress versus slip; (b) maximum bond stress versus corrosion penetration reinforcement with larger covers. In these tests, they measured an increase in bond strength for increasing corrosion levels, and report as much as 7.5 times the bond capacity of uncorroded specimens. Fang et al. ${ }^{16}$ made similar tests, and found that the bond strength increased to 2-3 times the capacity of uncorroded specimens already for rather low corrosion levels. This higher capacity was maintained also for further increase of the corrosion level.

In conclusion, for the case with smooth bars, transverse reinforcement and where the cover does not crack at uncorroded pull-out, corrosion will increase the bond capacity, in some cases quite a lot.

\section{Without transverse reinforcement; cover cracks at uncorroded pull-out}

For very small covers, the cover might crack at uncorroded pull-out. If no transverse reinforcement is present, the pull-out failure will become rather brittle owing to the splitting failure.

This case was analysed using a concrete cover of $20 \mathrm{~mm}$, that is, similar to the corresponding case with transverse reinforcement. The results from these analyses are shown in Fig. 14. For uncorroded pull-out, a splitting crack reached the outer surface of the concrete when the bond stress reached its maximum around 4.2 $\mathrm{MPa}$. As there was no transverse reinforcement keeping the structure together, this resulted in a rather brittle failure. Corrosion alone cracked the cover at a corrosion penetration around $15 \mu \mathrm{m}$. Corrosion in-

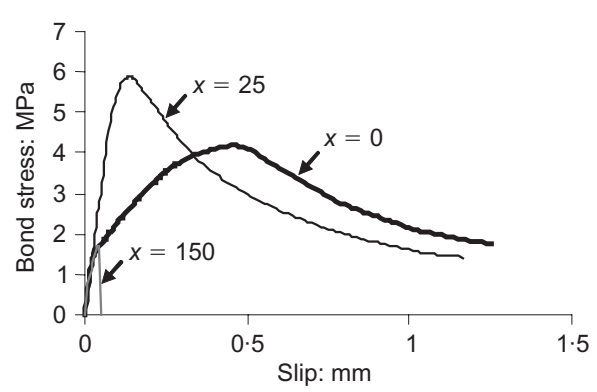

(a)

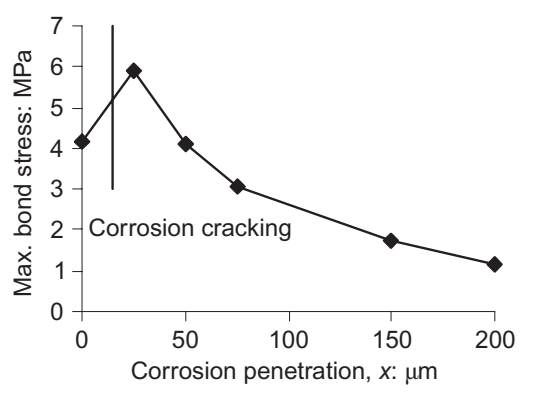

(b)

Fig. 14. Results from analyses with smooth bars without transverse reinforcement; cover cracks at uncorroded pullout. Cover $20 \mathrm{~mm}$, bar diameter $20 \mathrm{~mm}$ : (a) bond stress versus slip; (b) maximum bond stress versus corrosion penetration 
creased the initial stiffness in the bond-slip behaviour. The maximum bond capacity increased slightly by corrosion for corrosion penetrations that did not crack the cover; however, for larger corrosion penetrations, the bond capacity decreased to almost zero.

To conclude, for the case without transverse reinforcement and where the cover cracks at uncorroded pullout, very limited corrosion will crack the cover. Thereafter, corrosion will decrease the bond capacity.

No tests have been found in the literature with smooth bars and cover cracking at uncorroded pull-out, most probably because this is not a very common case.

Without transverse reinforcement; cover does not crack at uncorroded pull-out

The situation where the cover does not crack at uncorroded pull-out is a common situation in real structures with smooth bars. Furthermore, it is also rather common, especially in older structures, that there is no transverse reinforcement.

This case was investigated in axisymmetric analyses using a concrete cover of $40 \mathrm{~mm}$, that is, similar to the corresponding case with transverse reinforcement. The results from these analyses are shown in Fig. 15. In the analysis without corrosion, a pull-out failure was obtained with a maximum bond capacity around 5.5 MPa. Corrosion cracked the cover at a corrosion penetration around $40 \mu \mathrm{m}$. At this corrosion penetration, the bond strength increased to about $10 \mathrm{MPa}$. For corrosion penetrations larger than that, the bond capacity decreased abruptly, and as the failure mode changed from pull-out

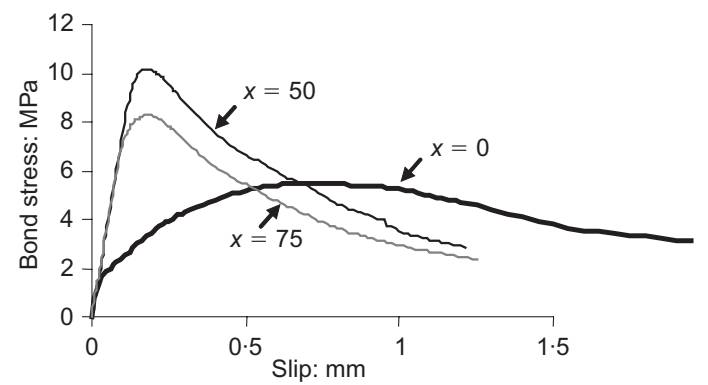

(a)

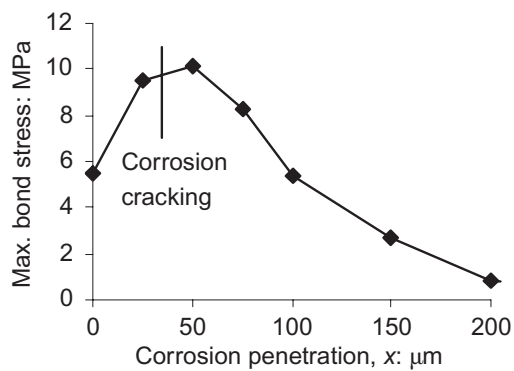

(b)

Fig. 15. Results from analyses with smooth bars, without transverse reinforcement; cover does not crack at uncorroded pull-out. Cover $40 \mathrm{~mm}$, bar diameter $20 \mathrm{~mm}$ : (a) bond stress versus slip; (b) maximum bond stress versus corrosion penetration to splitting failure, a brittle failure was obtained instead of the ductile behaviour obtained for smaller corrosion penetrations. Corrosion increased the initial stiffness in the bond-slip behaviour; thus, the more corrosion, the smaller the slip when the maximum bond stress was reached.

These results can be compared to results by Fang et $a l .{ }^{16}$ who made concentric pull-out tests without transverse reinforcement. An initial increase in bond strength at small corrosion levels changed into a decreasing capacity at larger corrosion levels. However, in these tests, the bond capacity was not smaller than for the uncorroded specimens even at corrosion levels as high as $9 \%$. Cairns et al. ${ }^{27}$ carried out eccentric pull-out tests. Even though the scatter in these tests was rather large, some tendencies could be seen. For the top-cast bars, the bond strength increased to the level of bottom-cast bars at a corrosion level around $50 \mu \mathrm{m}$. At higher corrosion levels, the bond capacity decreased gradually, both for top-cast and bottom-cast bars.

Thus, for the case with smooth bars, without transverse reinforcement and where the cover does not crack at uncorroded pull-out, the bond capacity and ductility will be decreased when the corrosion cracks the cover. For smaller corrosion penetrations, the bond capacity increases. As the analyses presented here are axisymmetric, they can be expected to be more sensitive to cracking than is to be expected in real structures, as the concrete surrounding the reinforcement there does not crack in all directions at the same time.

\section{General comments}

The behaviour for all different cases is summarised in Fig. 5. Generally, the bond capacity of smooth bars is less than for ribbed bars; however, for corrosion penetrations that do not crack the cover, the bond capacity can be increased to almost the same level as for ribbed bars.

The variation of the effect on the bond capacity can be seen in Fig. 16(a), where the maximum bond stress from the various analyses with smooth bars is plotted versus corrosion penetration. Similarly to ribbed bars, transverse reinforcement makes the bond much less sensitive to corrosion. Bond versus slip at various corrosion levels for the different analysed situations is shown in Figs 16(b)-(d).

\section{Differences in bond behaviour of ribbed and smooth bars}

In Figs 17(a) and (b), the failure surfaces at pull-out failure for uncorroded ribbed and smooth bars obtained in experiments are compared. As can be seen, at pullout failure of ribbed bars the failure takes place in the concrete between the ribs, while for smooth bars the failure takes place at the bar-concrete interface at pullout failure. The corresponding paths in the stress space 


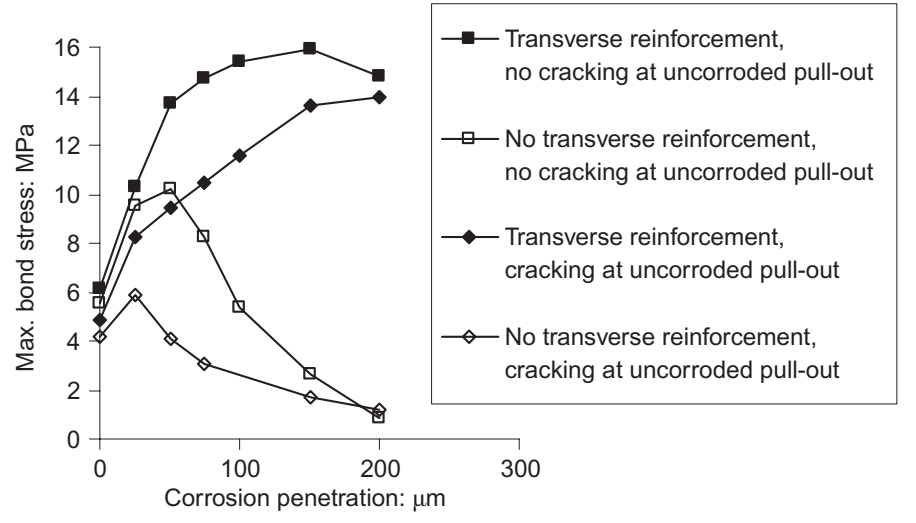

(a)

(c)

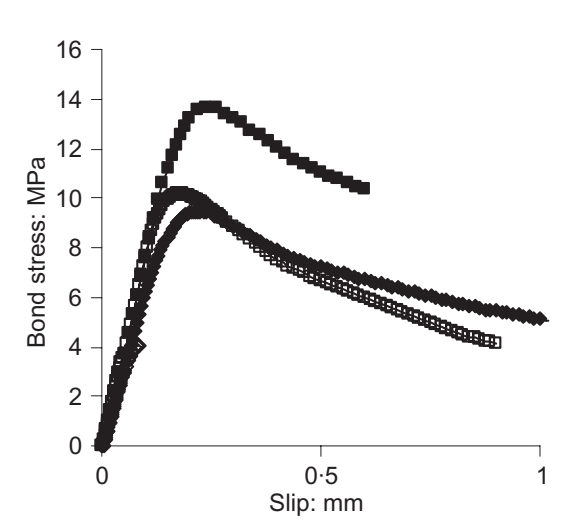

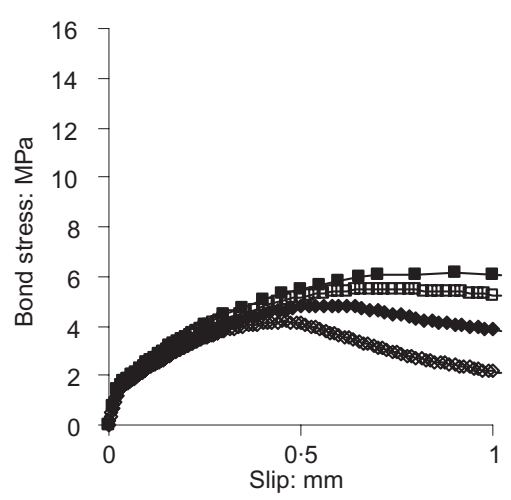

(b)

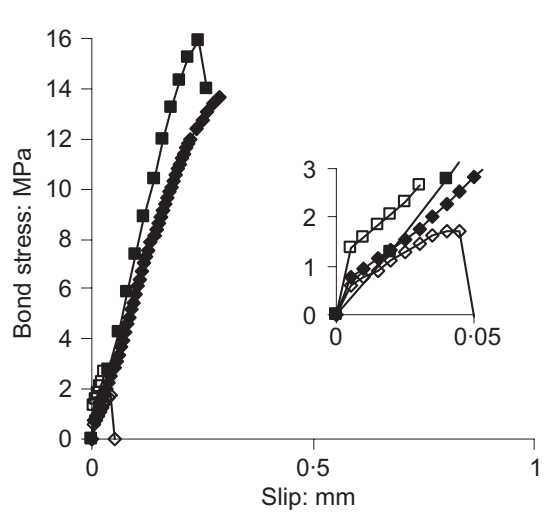

(d)

Fig. 16. Results from axisymmetric analyses with smooth bars. (a) Maximum bond stress versus corrosion penetration; (b), (c) and (d) bond stress plotted against slip at; (b) zero corrosion, (c) $50 \mu \mathrm{m}$ and (d) $150 \mu \mathrm{m}$, first part also enlarged

of the model are shown in Fig. 17(c). As can be seen, the maximum bond capacity at pull-out failure of a ribbed bar is limited by the upper limit determined from the stress in the inclined compressive struts that result from the bond action. This corresponds to failure of the concrete between the ribs. However, for smooth bars, it is instead the limited ability of the bar to cause normal stresses that limits the maximum bond capacity at pull-out failure.

Hence, a change in properties for the reinforcement or the concrete will not affect the load behaviour in the same manner for smooth bars as for deformed bars. For example, it is of great importance for the bond behaviour of smooth bars how dense the concrete close to the bars is, since this influences the ability of the bar to cause normal pressure. Therefore, concrete with the same compressive strength, but different mix proportions, might show different bond behaviour for smooth bars, and the concrete's degree of compacting is more important for the smooth bars. This explains why there is a larger difference between top-cast and bottom-cast bars for smooth than for ribbed bars. For ribbed bars, the compressive strength has more influence on the bond capacity; in the case of pullout failure, the bond capacity is even directly related to the compressive strength. This means that while the bond strength for ribbed bars will increase with concrete strength, this is not necessarily true for smooth bars.
Concerning the reinforcement, the roughness of the surface of smooth bars is of great importance for the bond behaviour. For ribbed bars, the detailing of the ribs does not have any major influence on the bond capacity; however, different detailing is likely to affect the stiffness of the first part in a bond versus slip curve.

Another difference between bonds of ribbed and smooth bars in concrete is the effect of an active confinement, for example a support pressure. For ribbed bars, the presence of support pressure will increase the bond capacity to the pull-out level. If there are splitting cracks, without support pressure, the capacity would be increased by a support pressure. However, if there is not any splitting crack without support pressure, a support pressure will not influence the capacity; it will remain the same. For smooth bars, support pressure will increase the bond capacity regardless of whether there would be splitting cracks without confinement or not. Still, the capacity cannot be larger than the upper limit determined by the stress in the compressive struts; but that is a large increase compared to the pull-out failure of a smooth bar without active confinement.

There are also similarities in the bond behaviour of ribbed and smooth bars. As has been shown, the same basic mechanisms are active, but they are of different magnitude, and therefore different mechanisms will determine the behaviour. One similarity is that both ribbed 


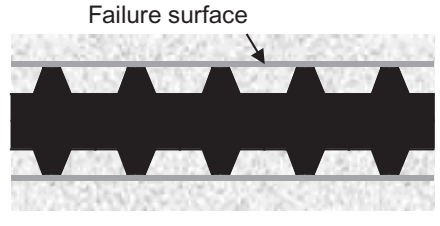

(a)

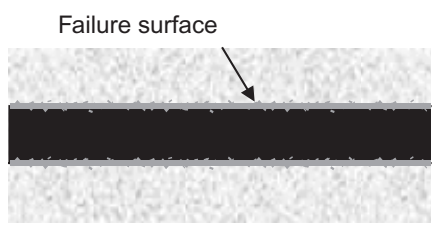

(b)

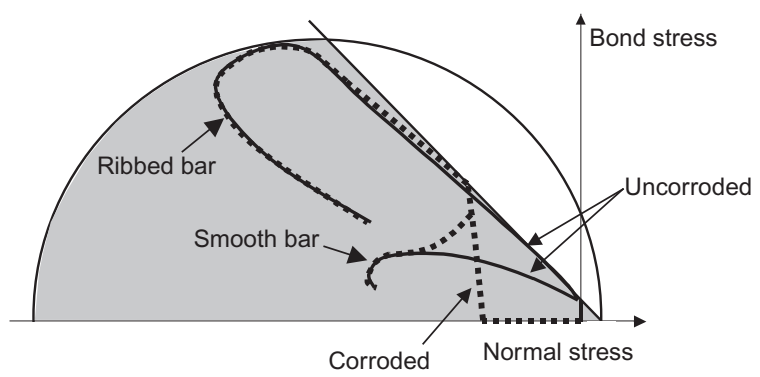

(c)

Fig. 17. Failure surface in the case of pull-out failure of (a) a ribbed bar and (b) a smooth bar and (c) the corresponding paths in stress space

and smooth bars generate splitting stresses, although ribbed bars generate more. Even so, splitting failure may occur for both types, leading to loss of bond in a similar manner. Another similarity is the loss of bond which is obtained if yielding of the reinforcement is reached.

Concerning the effect of corrosion, it has basically the same effect on both smooth and ribbed bars: due to the volume increase, splitting stresses will appear. Owing to the differences in behaviour for ribbed and smooth bars, however, this will affect the bond mechanism in slightly different ways. The paths described in the stress space by corrosion and thereafter subsequent pull-out are shown in Fig. 17(c), still assuming that pull-out failure is the limiting failure mode. For both ribbed and smooth bars, the corrosion will cause an initial increase in normal stresses, before any pull-out force is applied. For ribbed bars, the bond capacity will not be much affected, as it is still limited by the stress in the inclined compressive struts. For smooth bars, on the other hand, the bond capacity will increase, as the increase in normal stresses will have a direct influence on the bond stresses that can be carried by friction.

\section{Conclusions}

Studies of the mechanisms of bond and effect of corrosion show that the same basic mechanisms are active for both ribbed and smooth bars. However, the basic mechanisms are of different magnitude, and therefore different mechanisms determine the behaviour. Generally, the bond capacity of smooth bars is less than for ribbed bars, mainly because the capacity of smooth bars is limited by the limited ability of the bar to generate normal stresses at slip. Therefore corrosion, as long as it does not crack the cover, can increase the bond capacity of smooth bars to about the level of ribbed bars. For ribbed bars, corrosion might increase the bond capacity, but only to a minor extent. High corrosion levels will damage the bond, especially if transverse reinforcement is not supplied.

An overview of the effect of corrosion on bond is shown in Fig. 5. For both ribbed and smooth bars, transverse reinforcement makes the bond behaviour much less sensitive to corrosion. This is logical, as the transverse reinforcement will limit the splitting cracks that may arise due to the corrosion. Another general observation is that corrosion increases the initial stiffness for all cases. The effect on the bond capacity varies more. In short, the following conclusions can be drawn.

(a) For ribbed bars with transverse reinforcement, where the cover would crack for an uncorroded bar loaded in pull-out: corrosion causes small bond decrease, or does not influence the bond capacity.

(b) For ribbed bars with transverse reinforcement, where the cover would not crack for an uncorroded bar loaded in pull-out: corrosion causes small increase in bond capacity until the cover cracks; for larger corrosion levels the bond capacity decreases or remains approximately equal.

(c) For ribbed bars without transverse reinforcement, where the cover would crack for an uncorroded bar loaded in pull-out: bond capacity decreases already for low corrosion levels.

(d) For ribbed bars without transverse reinforcement, where the cover would not crack for an uncorroded bar loaded in pull-out: corrosion causes small increase in bond capacity until the cover cracks; for larger corrosion levels the bond capacity decreases abruptly. Also the ductility decreases after cover cracking.

(e) For smooth bars with transverse reinforcement, where the cover would crack for an uncorroded bar loaded in pull-out: corrosion causes small increase of bond capacity.

$(f)$ For smooth bars with transverse reinforcement, where the cover would not crack for an uncorroded bar loaded in pull-out: corrosion increases the capacity until the cover cracks. This increase can be substantial, especially for large covers. Larger corrosion levels cause small bond increase or do not further influence the bond capacity.

(g) For smooth bars without transverse reinforcement, where the cover would crack for an uncorroded bar

Magazine of Concrete Research, 2007, 59, No. 6 
loaded in pull-out: corrosion decreases the bond capacity.

(h) For smooth bars without transverse reinforcement, where the cover would not crack for an uncorroded bar loaded in pull-out: corrosion increases the capacity until the cover cracks, while larger corrosion levels decrease the bond capacity and ductility.

These conclusions can be used to better understand the mechanisms of bond and corrosion. Furthermore, they will be useful as background information to give guidelines about assessment of existing structures. In planned future research, this overview will be a base for further studies, where the effects on bond owing to reinforcement corrosion will be quantified for various cases.

\section{Acknowledgements}

This research has been conducted within the European project 'Sustainable Bridges'. Financial support from the $6^{\text {th }}$ Framework Programme of the European Commission and from the Swedish Rail Administration is gratefully acknowledged.

\section{References}

1. Duracrete. General guidelines for durability design and redesign. Duracrete. Probabilistic Performance based Durability Design of Concrete Structures. Document BE95-1347/R15. The European Union, Brite EuRam III, 2000.

2. FÉdÉRATion Internationale du BÉton. Bond of reinforcement in concrete, State-of-art report. FIB bulletin 10. FIB, Lausanne, 2000.

3. Li C. Q. and Zheng J. J. Propagation of reinforcement corrosion in concrete and its effects on structural deterioration. Magazine of Concrete Research, 2005, 57, No. 5, 261-271.

4. Lundgren K. Modelling the effect of corrosion on bond in reinforced concrete. Magazine of Concrete Research, 2002, 54, No. 3, 165-173.

5. Lundgren K. Bond between ribbed bars and concrete. Part 2: the effect of corrosion. Magazine of Concrete Research, 2005, 57, No. 7, 383-396.

6. Berra M., Castellani A., Coronelli D., Zanni S. and ZHANG G. Steel-concrete bond deterioration due to corrosion: finite element analysis for different confinement levels. Magazine of Concrete Research, 2003, 55, No. 3, 237-247.

7. American Concrete Institute. ACI 408.2R-92. State-of-theArt Report on Bond Under Cyclic Loads. ACI, Michigan, 1992. ACI Committee 408.

8. Magnusson J. Bond and Anchorage of Ribbed Bars in HighStrength Concrete. PhD Thesis, Division of Concrete Structures, Chalmers University of Technology, Göteborg, 2000.

9. Lundgren K. Bond between ribbed bars and concrete. Part 1: Modified model. Magazine of Concrete Research, 2005, 57, No. 7, 371-382.

10. BolmsviK R. and Lundgren K. Modelling of bond between three-wire strands and concrete. Magazine of Concrete Research, 2006, 58, No. 3, 123-133.

11. Cairns J., Du Y. and Johnston M. Bond of plain bars affected by corrosion. In Proceedings to Mark 60th Birthday of Prof. $R$. Eligehausen (Fuchs W. and ReinhardT H.-W., (eds)). Verlag, Stuttgart, Germany, 2002, pp. 129-136.
12. Ouglova A., Berthaud Y., François M. and Foct F. Mechanical properties of an iron oxide formed by corrosion in reinforced concrete structures. Corrosion Science, 2006, 48, No. 12, 3988-4000.

13. Netherlands Organisation for Applied Scientific ReSEARCH (TNO). DIANA Finite Element Analysis, User's Manual Release 8.1. TNO Building and Construction Research, Delft, 2002.

14. Comité Euro-International du Béton. CEB-FIP model code 1990. Bulletin d'Information, Nos 213/214. CEB Lausanne, Switzerland, 1993.

15. Al-Sulaimani G. J., Kaleemullah M., Basunbul I. A. and RASHEEDUZZAFAR. Influence of corrosion and cracking on bond behavior and strength of reinforced concrete members. ACI Structural Journal, 1990, 87, No. 2, 220-231.

16. FAng C., Lundgren K., Chen L. and Zhu C. Corrosion influence on bond in reinforced concrete. Cement and Concrete Research, 2004, 34, No. 11, 2159-2167.

17. Lee H.-S., Noguchi T. and Tomosawa F. Evaluation of the bond properties between concrete and reinforcement as a function of the degree of reinforcement corrosion. Cement and Concrete Research, 2002, 32, No. 8, 1313-1318.

18. Coronelli D. Bar Corrosion in Steel-Concrete Bond: Material and Structural Effects in $R / C$. PhD Thesis, Structural Engineering Department, Politecnico di Milano, Milano, 1998.

19. Shima H. Local bond stress relationship of corroded steel bars embedded in concrete. In Bond in Concrete: From Research to Standards (Balazs G. L., Bartos P. J. M., Cairns J. and Borosnyoi A. (eds)). Publishing company of Budapest University of Technology and Economics, Budapest, 2002, pp. $153-$ 158.

20. Mangat P. S. and Elgarf M. S. Bond characteristics of corroding reinforcement in concrete beams. Materials and Structures/ Materiaux et Constructions, 1999, 32, No. 216, 89-97.

21. Auyeung Y., Balaguru P. and Chung L. Bond behavior of corroded reinforcement bars. ACI Materials Journal, 2000, 97, No. 2, 214-220.

22. Stanish K., Hooton R. D. and Pantazopoulou S. J. Corrosion effects on bond strength in reinforced concrete. ACI Structural Journal, 1999, 96, No. 6, 915-921.

23. Ghandehari M., Zulli M. and Shah S. P. Influence of corrosion on bond degradation in reinforced concrete. In Proceedings EM2000, Fourteenth Engineering Mechanics Conference, Austin, Texas (Tassoulas J. (ed.)). American Society of Civil Engineers, Reston, VA, USA, 2000 (CD-ROM).

24. Almusallam A. A., Al-Gahtani A. S. and Aziz A. R. Effect of reinforcement corrosion on bond strength. Construction and Building Materials, 1996, 10, No. 2, 123-129.

25. Cabrera J. G. and Ghoddoussi P. The effect of reinforcement corrosion on the strength of the steel/concrete 'bond'. In Bond in Concrete, Proceedings of an International Conference, Riga (Skudra A. and Tepfers R. (eds)). Comité Euro-International du Béton, Paris, 1992, pp. 10-11-10-24.

26. Hussein N.-A., Yang Y., Kawai K. and Sato R. Time dependent bond behaviour of corroded bars. In Bond in Concrete: From Research to Standards (BALAzs G. L., Bartos P. J. M., Cairns J. and Borosnyol A. (eds)). Publishing company of Budapest University of Technology and Economics, Budapest, 2002, pp. 166-173.

27. CaIRns J., Du Y. and Johnston M. Residual bond capacity of corroded plain surface reinforcement. In Bond in Concrete: From Research to Standards (Balazs G. L., Bartos P. J. M., CaIrns J. and Borosnyol A. (eds)). Publishing company of Budapest University of Technology and Economics, Budapeset, 2002, pp. 129-136.

Discussion contributions on this paper should reach the editor by 1 February 2008 